\title{
Self-Reported Changes in Weight, Food Intake, and Physical Activity from High School to College
}

\author{
Charlotte Filla, Nicholas P Hays, Dana Gonzales and Reza Hakkak* \\ Dietetics and Nutrition, University of Arkansas for Medical Sciences, 4301 West Markham St., Slot \# 627, Little Rock, AR 72205, USA
}

\begin{abstract}
The purpose of this study was to examine body weight, dietary intake, and physical activity among first-year students during the transition from high school to college. First-year students $(n=28)$ at a public university in central Arkansas completed an online survey that assessed demographic, height, weight, diet, and physical activity information. The survey was administered during the spring semester of the 2009 academic year, with participants instructed to report current (i.e. collegiate) and retrospective (i.e. final year of high school) information. Current weight was greater than recalled high school weight $(+2.7 \mathrm{~kg}, p=0.008)$. Dietary intake as assessed by reported frequency of consumption of selected food items was significantly decreased in college relative to high school for three foods: milk ( -0.17 times/day, $p=0.013)$, cheese $(-0.27, p=0.012)$, and red meat $(-0.18, p=0.006)$. Time spent participating in vigorous-intensity physical activity was also significantly less in college compared to high school $(p<0.05)$, although time spent walking or bicycling for transportation was significantly increased from $5.6 \pm 16.1 \mathrm{~min} / \mathrm{d}$ in high school to $49.5 \pm 57 \mathrm{~min} / \mathrm{d}$ in college $(p<0.001)$. These results indicate that students in this population experienced moderate weight gain during their first year in college, in conjunction with a decrease in vigorous-intensity physical activity and modest changes in food intake. Weight gain occurred despite large increases in time spent walking and bicycling for transportation. Interventions to increase vigorous physical activity, especially activities beyond walking and bicycling, may be particularly important in preventing weight gain in this population.
\end{abstract}

Keywords: College students; Diet; Physical activity; Weight gain; Walking; Bicycling, Freshman 15

Abbreviations: GPAC: Global Physical Activity Questionnaire; SD: Standard Deviation; MET: Metabolic Equivalent Tasks

\section{Introduction}

The concept that first-year students gain a substantial amount of weight during their initial year of college is popularized as the "Freshman 15 " and remains pervasive despite evidence that weight gain of this magnitude (i.e. 15 pounds) is actually uncommon [1,2]. According to a recent study [3], male college students gain approximately $1.8 \mathrm{~kg}$ $(4 \mathrm{lb})$ and female students gain $0.9 \mathrm{~kg}(2 \mathrm{lb})$ during their initial year of school, which is generally consistent with the magnitude of weight gain reported in earlier studies [4-7]. Although some weight gain may be expected in this population as a part of normal growth and development, excess weight gain should be prevented given the strong association of overweight and obesity with negative health outcomes [8] and the difficulties in losing weight and maintaining a reduced body weight following acute weight loss [9].

The transition from high school to the first year of college is a crucial period for potential weight gain among students, given their exposure to new food and physical activity environments. While certain environmental influences that may contribute to overeating are similar among high-school and college students (e.g. exposure to energy-dense snack foods and sugar-sweetened beverages that are often readily available in the school environment), college students frequently have additional environmental factors that may promote excess energy intake, including increased independence from parental supervision at meal time, larger meal portions, and "all-you-can-eat" University dining facilities [10]. In addition, college students may be more sedentary due to an increased academic workload compared to high school. Previous studies examining diet and activity in relation to first-year student weight gain (both self-reported and measured) have been somewhat conflicting, with one study reporting that weight gain during this interval was the result of decreased physical activity rather than increased energy intake [11], while another found that a healthful eating behaviors rather than exercise was the greater challenge to maintain in college [12].Other examinations of eating patterns [13], snacking behavior [14], and psychosocial factors [5,15] have been completed in college students in an attempt to identify specific factors responsible for this weight gain, but detailed assessments of dietary and physical activity in students during the transition from high school to the first year of college are limited. Thus, the relative importance of physical activity versus dietary intake in influencing weight gain over this transition period from high school to college remains uncertain.

The purpose of this study was to examine changes in body weight, food intake, and physical activity in young men and women between their senior year of high school and their first year of college. We hypothesized that first-year students would self-report an increase in body weight over the transition from the senior year of high school to the first year of college due to increased frequency of consumption of energy-dense and high-fat foods and decreased frequency and amount of physical activity.

\section{Materials and Methods}

\section{Participants and Setting}

Students in their first year of school at a public Arkansas university were recruited to participate in the study. Undergraduate enrollment

${ }^{*}$ Corresponding author: Dr. Reza Hakkak, Department of Dietetics and Nutrition University of Arkansas for Medical Sciences, 4301 West Markham St., Slot \# 627, Little Rock, AR 72205, USA, Tel: 501-686-6166; Fax: 501-686-5716; E-mail: rhakkak@uams.edu

Received July 24, 2013; Accepted September 25, 2013; Published September 27, 2013

Citation: Filla C, Hays NP, Gonzales D, Hakkak R (2013) Self-Reported Changes in Weight, Food Intake, and Physical Activity from High School to College. J Nutr Disorders Ther 3: 129. doi:10.4172/2161-0509.1000129

Copyright: @ 2013 Hakkak R, et al. This is an open-access article distributed unde the terms of the Creative Commons Attribution License, which permits unrestricted use, distribution, and reproduction in any medium, provided the original author and source are credited. 
during the time of data collection (2010) was $\sim 9,300$ students, and the university campus comprises an area of about $2 \mathrm{~km}^{2}$ located in an urbanized area (total population $\sim 50,000$ ). Subjects were recruited using multiple methodologies, including through flyers displayed on campus, personal contact with study personnel in first-year classes and the cafeteria, communication with professors of first-year courses who announced the study and how to participate in their classes, and by using advertisements on the University's Facebook page and campus-wide e-mails from professors, residential services, the athletic director and Pan-Hellenic executives. The flyers and e-mail invitations contained a description of the study, provided the web URL to access the online survey directly, and included the principal investigator's e-mail address so prospective subjects could contact the investigator with any questions or concerns.

\section{Inclusion/exclusion criteria}

Subjects were eligible for the study if they were unmarried first-year university students within the age range of 18 to 22 years, if they lived on-campus or in a house or apartment with peers, and were not pregnant or lactating. Survey responses from 36 subjects were received. Subjects who did not complete all survey questions $(n=8)$ were excluded from further analyses, leaving a final sample size of 28. Subjects provided informed electronic consent for their participation. They were assured that survey responses were anonymous and that participation or nonparticipation would not affect their evaluations, entitlements, or rights. Subjects were not compensated for their participation in the study. The Institutional Review Boards of both the University of Arkansas for Medical Sciences (the home institution of the investigators) and the undergraduate University where data were collected classified study procedures as exempt.

\section{Design}

The study design was cross-sectional. Students completed an online survey (SurveyMonkey.com, Palo Alto, CA) during the spring semester of the 2009 academic year. In the first section of the survey, subjects were instructed to provide a retrospective recall of dietary intake and physical activity behaviors during their senior year of high school. In the second section of the survey, subjects were instructed to respond based on current (i.e. collegiate) diet and physical activity habits. The primary outcomes were body weight, physical activity, and dietary intake during each reporting interval. The sampling design used was a non-probability purposive sample.

\section{Survey instruments}

General survey questions included the subject's self-reported height and weight, gender, ethnicity, intended major, residential arrangement, organized sports participation in high school, and collegiate sports participation. The survey also included the Multifactor Screener [16] to assess reported dietary intake and the Global Physical Activity Questionnaire version 2.0 (GPAQ) $[17,18]$ to assess reported physical activity. The Multifactor Screener provides information regarding the frequency of consumption of selected foods and beverages. The GPAQ provides information regarding the frequency and duration of vigorous- and moderate-intensity physical activity, as well as walking and bicycling transportation activities. Both survey instruments have been previously tested and found to be valid and reliable indicators of dietary intake and physical activity, respectively $[19,20]$. Permission to modify the GPAQ to more clearly assess activity among college students and reproduce the survey electronically was obtained from the World Health Organization.

\section{Statistical analysis}

Statistical analyses were conducted using SPSS version 12.0 (SPSS Inc., Chicago, IL).The shape of the data distribution for each variable was determined using visual inspection of stem-and-leaf plots and the Shapiro-Wilk test of normality. A paired t-test was used to analyze mean differences between high school and college data that were normally distributed, while the Wilcoxon signed rank test was used analyze data that were not normally distributed. Independent $t$-tests were used to assess differences between men and women or other categories, where appropriate. A $p$-value $<0.05$ was considered statistically significant.

\section{Results}

Of the 28 subjects who submitted evaluable survey responses without missing data, 20 respondents (71\%) were female and $8(29 \%)$ were male. Ages ranged from 18 to 22 years by design, with a mean age of $19.1 \pm 1.1$ years. Eighteen $(64 \%)$ of the students were white/ Caucasian, 8 (29\%) were African-American, and 2(7\%) were Hispanic/Latino. By design, all subjects were first-year university students, unmarried, not pregnant or lactating, and lived in university dormitories $(n=22)$ or houses/apartments with peers $(n=6)$.

\section{Changes in body weight}

A significant increase in body weight from high school to the first year of college was reported $(+2.7 \pm 4.9 \mathrm{~kg}[6.0 \pm 10.9 \mathrm{lbs}], p=0.008)$, as shown in Table 1. Body weight of male subjects increased on average by $2.6 \mathrm{~kg}$ and weight of females increased by $2.7 \mathrm{~kg}$. A wide range of weight change was found among the group varying from -6.8 to + $13.6 \mathrm{~kg}$. The majority of students ( $n=20 ; 15$ women and 5 men) gained weight (range $=0.9-13.6 \mathrm{~kg}$ ). The average gain for students in this group was $4.9 \mathrm{~kg}$, with men's weight increasing by $5.0 \mathrm{~kg}$ and women's by $4.8 \mathrm{~kg}$. Only 8 respondents ( 5 women and 3 men) reported weight maintenance or weight loss over this time interval, with an average loss of $2.7 \mathrm{~kg}$ ( $1.4 \mathrm{~kg}$ for men and $3.5 \mathrm{~kg}$ for women).

\begin{tabular}{|c|c|c|c|}
\hline & Total sample & Subjects who gained weight & Subjects who lost or maintained weight \\
\hline Measure & $(n=28)$ & $(n=20)$ & $(n=8)$ \\
\hline High school weight (kg) & $71.9 \pm 15.5$ & $67.1 \pm 11.7$ & $84.0 \pm 20.0^{\mathrm{a}}$ \\
\hline College weight (kg) & $74.6 \pm 15.1^{b}$ & $72.0 \pm 13.1^{b}$ & $81.2 \pm 18.5^{b}$ \\
\hline Difference & $+2.7 \pm 4.9$ & $+4.9 \pm 3.9$ & $-2.7 \pm 2.4$ \\
\hline High school BMI (kg/m²) & $25.3 \pm 5.2$ & $24.0 \pm 4.1$ & $28.5 \pm 6.5^{\mathrm{a}}$ \\
\hline College BMI (kg/m²) & $26.3 \pm 5.3^{b}$ & $25.8 \pm 4.8^{b}$ & $27.6 \pm 6.6^{b}$ \\
\hline Difference & $+1.0 \pm 1.8$ & $+1.8 \pm 1.4$ & $-0.9 \pm 0.8$ \\
\hline
\end{tabular}

Notes: data are shown as mean \pm standard deviation; $\mathrm{BMI}=$ body mass index

a Significant difference $(p<0.05)$ from corresponding value among students who gained weight.

b Significant difference $(p<0.05)$ from corresponding high school value in column.

Table 1: Reported body weight in high school and first year of college. 
Citation: Filla C, Hays NP, Gonzales D, Hakkak R (2013) Self-Reported Changes in Weight, Food Intake, and Physical Activity from High School to College. J Nutr Disorders Ther 3: 129. doi:10.4172/2161-0509.1000129

Page 3 of 5

\begin{tabular}{|c|c|c|c|c|}
\hline Food category & High school & College & Differences & $p$-value \\
\hline Cold cereal & $0.36 \pm 0.31$ & $0.31 \pm 0.33$ & $-0.06 \pm 0.32$ & 0.238 \\
\hline Milk & $0.59 \pm 0.60$ & $0.42 \pm 0.67$ & $-0.17 \pm 0.41$ & 0.013 \\
\hline Cheese & $0.83 \pm 0.83$ & $0.56 \pm 0.69$ & $-0.27 \pm 0.54$ & 0.012 \\
\hline Bacon or sausage & $0.20 \pm 0.22$ & $0.14 \pm 0.16$ & $-0.07 \pm 0.24$ & 0.166 \\
\hline Hot dogs & $0.12 \pm 0.11$ & $0.09 \pm 0.11$ & $-0.03 \pm 0.13$ & 0.118 \\
\hline Red meat & $0.45 \pm 0.44$ & $0.28 \pm 0.42$ & $-0.18 \pm 0.29$ & 0.006 \\
\hline Whole grain bread & $0.99 \pm 0.89$ & $0.88 \pm 0.88$ & $-0.11 \pm 0.36$ & 0.148 \\
\hline $100 \%$ fruit juice & $0.37 \pm 0.65$ & $0.27 \pm 0.41$ & $-0.10 \pm 0.48$ & 0.405 \\
\hline Fruit & $0.48 \pm 0.58$ & $0.45 \pm 0.53$ & $-0.03 \pm 0.49$ & 0.529 \\
\hline Regular fat salad dressing or mayo & $0.22 \pm 0.20$ & $0.23 \pm 0.24$ & $+0.01 \pm 0.20$ & 0.803 \\
\hline Lettuce or salad & $0.31 \pm 0.41$ & $0.39 \pm 0.50$ & $+0.08 \pm 0.42$ & 0.472 \\
\hline French fries /hash browns & $0.42 \pm 0.63$ & $0.32 \pm 0.38$ & $-0.10 \pm 0.39$ & 0.283 \\
\hline White potatoes & $0.19 \pm 0.16$ & $0.21 \pm 0.20$ & $+0.02 \pm 0.24$ & 0.822 \\
\hline Beans & $0.13 \pm 0.11$ & $0.14 \pm 0.13$ & $+0.02 \pm 0.09$ & 0.272 \\
\hline Vegetables & $0.58 \pm 0.79$ & $0.63 \pm 0.75$ & $+0.06 \pm 0.96$ & 0.531 \\
\hline Pasta & $0.39 \pm 0.30$ & $0.30 \pm 0.25$ & $-0.09 \pm 0.25$ & 0.062 \\
\hline Nuts and seeds & $0.14 \pm 0.21$ & $0.12 \pm 0.14$ & $-0.02 \pm 0.20$ & 0.721 \\
\hline Regular fat potato chips & $0.30 \pm 0.25$ & $0.21 \pm 0.22$ & $-0.09 \pm 0.30$ & 0.057 \\
\hline
\end{tabular}

Notes: Data are shown as mean \pm standard deviation

Table 2: Reported dietary intake (calculated as daily frequency of consumption) in high school and first year of college ( $n=28)$.

\begin{tabular}{|c|c|c|c|c|}
\hline Physical activity & High school & College & Delta & $p$-value \\
\hline \multicolumn{5}{|c|}{ Vigorous-intensity activities at school or work } \\
\hline Days / week & $2.3 \pm 2.5$ & $0.3 \pm 0.9$ & $-2.0 \pm 2.4$ & 0.001 \\
\hline Minutes / bout & $64.5 \pm 80.6$ & $6.1 \pm 19.1$ & $-58.4 \pm 83.5$ & 0.001 \\
\hline \multicolumn{5}{|c|}{ Vigorous-intensity activities during sports or recreation } \\
\hline Days / week & $4.0 \pm 2.7$ & $2.1 \pm 1.9$ & $-1.8 \pm 3.0$ & 0.003 \\
\hline Minutes / bout & $86.4 \pm 68.9$ & $55.7 \pm 58.7$ & $-30.7 \pm 69.9$ & 0.013 \\
\hline \multicolumn{5}{|c|}{ Moderate-intensity activities at school or work } \\
\hline Days / week & $3.0 \pm 2.4$ & $2.9 \pm 2.5$ & $-0.02 \pm 3.2$ & 0.951 \\
\hline Minutes / bout & $65.4 \pm 75.9$ & $31.1 \pm 41.9$ & $-34.3 \pm 90.8$ & 0.082 \\
\hline \multicolumn{5}{|c|}{ Moderate-intensity activities during sports or recreation } \\
\hline Days / week & $2.3 \pm 2.6$ & $2.3 \pm 1.8$ & $0 \pm 2.9$ & 0.667 \\
\hline Minutes / bout & $51.4 \pm 69.7$ & $51.1 \pm 49.5$ & $-0.4 \pm 67.2$ & 0.905 \\
\hline \multicolumn{5}{|c|}{ Walking or bicycling for transportation } \\
\hline Days / week & $0.7 \pm 1.9$ & $3.9 \pm 2.3$ & $+3.1 \pm 2.5$ & $<0.001$ \\
\hline Minutes / bout & $5.6 \pm 16.1$ & $49.5 \pm 57.0$ & $+43.9 \pm 59.1$ & $<0.001$ \\
\hline \multicolumn{5}{|c|}{ Sedentary behaviors or sitting } \\
\hline Hours / day & $7.6 \pm 3.9$ & $7.9 \pm 3.9$ & $+0.3 \pm 4.6$ & 0.777 \\
\hline
\end{tabular}

Notes: Data are shown as mean \pm standard deviation

Table 3: Reported physical activity in high school and first year of college $(n=28)$.

\section{Dietary intake}

As shown in Table 2, significant decreases in the frequency of milk (either to drink or on cereal), cheese (consumed as a snack, on sandwiches, or mixed into other foods), and red meat (beef, lamb, venison, hamburgers, steaks, but not fish or poultry) consumption were reported between high school and college. In high school, milk was consumed $0.59 \pm 0.60$ times per day (4.13 times per week) and in college it was consumed $0.42 \pm 0.67$ times per day (2.94 times / week; $p=0.013$ ). Thus, students reported consuming milk about 1 less time per week in the first year of college compared to their senior year of high school. Similarly, reported frequency of cheese consumption decreased in college compared to high school, from $0.83 \pm 0.83$ to 0.56 \pm 0.69 times per day $(p=0.012)$, representing a decrease in cheese intake of approximately 1.89 times per week. Frequency of red meat consumption also decreased in college. It was consumed $0.45 \pm 0.44$ times per day in high school and $0.28 \pm 0.42$ times per day in college $(p=0.006)$, representing a weekly decrease of 1.18 times per week. There were no significant differences between high school and college food consumption frequencies for any other surveyed food categories (Table 2).

\section{Physical activity}

The number of days per week of vigorous intensity activities at school or work per week decreased from 2.3 days $(\mathrm{SD} \pm 2.5)$ in high school to 0.3 days $(p=0.001)$ in college (Table 3$)$. The time spent for these activities decreased from 64.5 minutes $(S D \pm 80.6)$ in high school to 6.1 minutes $(S D \pm 19.1, p=0.001)$ in college. The number of days of vigorous intensity sports, fitness, or recreational activities decreased from 4.0 days ( $\mathrm{SD} \pm 2.7$ ) in high school to 2.1 days ( $\mathrm{SD} \pm 1.9, p=0.003$ ) in college. The time spent doing these activities decreased from 86.4 minutes $(\mathrm{SD} \pm 68.9)$ in high school to 55.7 minutes $(\mathrm{SD} \pm 58.7, p=0.013$ ) in college. 
In contrast, one area of physical activity increased for college students, which was number of days and time spent walking or bicycling for transportation. The number of days per week for these activities increased from 0.7 days $(\mathrm{SD}=1.9)$ in high school to 3.9 days $(\mathrm{SD}=2.3)$ in college. The time spent in these activities increased from 5.6 minutes $(\mathrm{SD}=16.1)$ in high school to 49.5 minutes $(S D=57.0, p<0.001)$ in college.

When calculating the total metabolic equivalent tasks (MET) in minutes per week that each student performed, it was found that the average high school student reported 8312 MET-minutes per week while the average value college student reported 4032 MET-minutes per week (data not shown), indicating that the subjects participated in less than half (49\%) of the same amount, duration, and intensity of physical activity participated in during high school, although the reported level of activity is still considered acceptable ( $\geq 1000$ MET-minutes per week).

\section{Discussion}

The purpose of this study was to examine the changes in body weight, food intake, and physical activity in students who transition from high school to college. The results indicate that there may be changes in these parameters as they transition from high school to college. In contrast to the concept that first-year students gain a substantial amount of weight during their initial year of college (popularized as the "Freshman 15 "), the current results indicated that average changes in weight were generally moderate. Although weight changes ranged from losing 6.8 $\mathrm{kg}$ (15 lbs) to gaining $13.6 \mathrm{~kg}$ (30 lbs), the mean was a weight gain of about $2.7 \mathrm{~kg}$ (6 lbs) for both men and women, which is slightly more than the average weight gain reported or measured in many previous studies. For example, Mihalopoulos et al. [4] and Gropper et al. [3] both reported an average gain of $1.2 \mathrm{~kg}$, Hajhosseini et al. [6] and Provencher et al. [15] both described average gains of approximately $1.5 \mathrm{~kg}$, HolmDenoma et al. [5] observed an average gain of $1.7 \mathrm{~kg}$, and Levitsky et al. [10] reported an average gain of $1.9 \mathrm{~kg}$ pounds, with a few studies $[12,21]$ reporting larger weight gains (e.g. $>2.7 \mathrm{~kg}$ ).

In an attempt to explore the underlying reasons for any observed changes in weight, subjects were surveyed on their dietary intake and physical activity. There was no significant change for any surveyed foods other than for milk, cheese, and red meat, which were each reported to be consumed approximately 1 fewer time per week during college as compared to high school. These changes may be due to environmental changes associated with college or volitional attempts to gain weight or muscle mass, but these factors were not assessed in the current study. The dietary survey instrument used in the current study (Multifactor Screener [16]) provides information on the frequency that each food item was eaten, but not the calories consumed; thus an increase in total energy intake consumption could be a likely cause of weight gain as well, but this parameter was not assessed.

With only minimal observed changes in dietary intake, the current results suggest that a reduction in physical activity may be associated with the changes in body weight. This suggestion is supported by the physical activity survey data, indicating that college students in the sample were expending less than half the METs they expended in high school. The frequency, duration, and intensity of physical activity decreased significantly from high school to college. Although walking or bicycling for transportation increased greatly in college, presumably due to walking to and from classes and other activities, it may not have been enough increase in physical activity to offset the lack of vigorous activities reported by the surveyed students.

The finding of physical activity being an important contributor to first-year student weight gain is similar to prior studies researching similar variables $[7,11,22]$. Decreased physical activity levels from high school to college were reported by Butler et al. [11], and hypothesized to be primarily responsible for the weight gain observed in that study. Racette et al. [7] suggested that the transition from participating in mainly aerobic exercises in high school to primarily stretching exercises in college was a contributor to freshman year weight gain because the amount of calories burned in stretching exercises is considerably lower than in aerobic exercises. Other studies that have focused on other potential causes of weight gain during this interval have suggested that decreases in physical activity play a major role in college weight gain $[6,12,21]$.

The present study has several limitations. The small sample size reduced the power to detect significant differences between the two tests for some variables and limits the generalizability of the results. Recruitment of subjects was difficult because there was no incentive offered, which resulted in the limited response rate. Previous studies have had sample sizes ranging from 27 subjects [6] to 1454 subjects [15], so although the current study is on the lower end of the sample size range, previous studies have had similar sample sizes. Also, because weight, diet, and physical activity were not observed directly, selfreport bias may have occurred. Our measure of dietary intake did not provide information on total calorie intake, which was also a potential limitation. Lastly, comparisons of weight, diet, and physical activity of first-year students with those of similarly-aged individuals not in college were not performed. Such a comparison could have allowed determination of how being in college affects weight change.

One potential strength of the study was the online administration of the questionnaires. Since college students are typically busy, it was convenient for the subjects to be able to complete the 20-minute survey in their own time and place. Electronic surveys have been shown to be valid for self-reported data collection [4].

\section{Conclusion}

This study examined change in body weight, food intake, and physical activity in young men and women during their transition from high school to college. Subjects were in their first year at a public university in Arkansas and lived on campus or in an apartment or house with peers. An average increase in weight of $2.7 \mathrm{~kg}$ for men and women was reported. Changes in dietary intake were generally minor, with decreases only reported for the intake of milk, cheese, and red meat servings per week. The number of days and amount of time spent participating in vigorous intensity activities during school, work, sports, or recreational activities decreased, but the amount of time spent walking and biking for transportation increased to a large extent. Since weight gain occurred despite large increases in time spent walking and bicycling for transportation, interventions to increase vigorous physical activity, especially activities beyond walking and bicycling, may be particularly important in preventing weight gain in this population.

\section{Acknowledgements}

The authors sincerely thank Gary Roberts, Ph.D. for assistance with subject recruitment, and Dean Robert Mc Gehee, Ph.D. and the UAMS Graduate School for study-related financial support. Ms Filla was a graduate student in clinica nutrition at the time this work was completed, and is currently a dietitian at the Texas Children's Hospital, Houston. Dr. Hays is currently employed by Nestlé Nutrition in King of Prussia, PA.

\section{Funding / Support}

This research was supported by the UAMS Graduate School and the Department of Dietetics and Nutrition. No potential conflict of interest was reported by the authors. 
Citation: Filla C, Hays NP, Gonzales D, Hakkak R (2013) Self-Reported Changes in Weight, Food Intake, and Physical Activity from High School to College. J Nutr Disorders Ther 3: 129. doi:10.4172/2161-0509.1000129

\section{References}

1. Miller $B$ (2009) How to avoid gaining the Freshman 15

2. Vella-Zarb RA, Elgar FJ (2009) The 'freshman 5': a meta-analysis of weight gain in the freshman year of college. J Am Coll Health 58: 161-166.

3. Gropper SS, Simmons KP, Connell LJ, Ulrich PV (2012) Weight and body composition changes during the first three years of college. J Obes 2012: 634048.

4. Mihalopoulos NL, Auinger P, Klein JD (2008) The Freshman 15: is it real? J Am Coll Health 56: 531-533.

5. Holm-Denoma JM, Joiner TE, Vohs KD, Heatherton TF (2008) The "freshman fifteen" (the "freshman five" actually): predictors and possible explanations. Health Psychol 27: S3-S9.

6. Hajhosseini L, Holmes T, Mohamadi P, Goudarzi V, McProud L, et al. (2006) Changes in body weight, body composition and resting metabolic rate (RMR) in first-year university freshmen students. J Am Coll Nutr 25: 123-127.

7. Racette SB, Deusinger SS, Strube MJ, Highstein GR, Deusinger RH (2008) Changes in weight and health behaviors from freshman through senior year of college. J Nutr Educ Behav 40: 39-42.

8. Bray GA (2004) Medical consequences of obesity. J Clin Endocrinol Metab 89 2583-2589.

9. Grief SN, Miranda RL (2010) Weight loss maintenance. Am Fam Physician 82 $630-634$

10. Levitsky DA, Halbmaier CA, Mrdjenovic G (2004) The freshman weight gain: model for the study of the epidemic of obesity. Int J Obes Relat Metab Disord 28: $1435-1442$.

11. Butler SM, Black DR, Blue CL, Gretebeck RJ (2004) Change in diet, physica activity, and body weight in female college freshman. Am J Health Behav 28 24-32.
12. Cluskey M, Grobe D (2009) College weight gain and behavior transitions: male and female differences. J Am Diet Assoc 109: 325-329.

13. Racette SB, Deusinger SS, Strube MJ, Highstein GR, Deusinger RH (2005) Weight changes, exercise, and dietary patterns during freshman and sophomore years of college. J Am Coll Health 53: 245-251.

14. Wansink B, Cao Y, Saini P, Shimizu M, Just DR (2013) College cafeteria snack food purchases become less healthy with each passing week of the semester. Public Health Nutr 16: 1291-1295.

15. Provencher V, Polivy J, Wintre MG, Pratt MW, Pancer SM, et al. (2009) Who gains or who loses weight? Psychosocial factors among first-year university students. Physiol Behav 96: 135-141.

16. National Cancer Institute (2009) Multifactor Screener in the 2000 NHIS Cancer Control Supplement (CCS).

17. Armstrong T, Bull F (2006) Development of the World Health Organization Global Physical Activity Questionnaire (GPAQ). J Public Health 14: 66-70.

18. World Health Organization (2009) Global Physical Activity Questionnaire.

19. Thompson FE, Midthune D, Subar AF, Kahle LL, Schatzkin A, et al. (2004) Performance of a short tool to assess dietary intakes of fruits and vegetables percentage energy from fat and fibre. Public Health Nutr 7: 1097-1105.

20. Bull FC, Maslin TS, Armstrong T (2009) Global physical activity questionnaire (GPAQ): nine country reliability and validity study. J Phys Act Health 6: 790-804

21. Hoffman DJ, Policastro P, Quick V, Lee SK (2006) Changes in body weight and fat mass of men and women in the first year of college: A study of the "freshman 15". J Am Coll Health 55: 41-45.

22. Jung ME, Bray SR, Martin Ginis KA (2008) Behavior change and the freshman 15: tracking physical activity and dietary patterns in 1st-year university women. J Am Coll Health 56: 523-530. 